Neuroimage. 2012 August 15; 62(2): 594-601. doi:10.1016/j.neuroimage.2012.01.103.

\title{
The Coupling Controversy
}

\author{
Peter T. Fox, M.D. \\ Research Imaging Institute and Department of Radiology, University of Texas Health Science \\ Center at San Antonio; South Texas Veterans Administration Medical Center
}

\begin{abstract}
Functional magnetic resonance imaging (fMRI) relies on the well-known phenomenon of coupling between neuronal activity and brain blood flow. For nearly a century, the presumption was that hemodynamics were coupled to neuronal activity via energy demand and oxidative metabolism. Early ${ }^{15} \mathrm{O}$ positron-emission tomographic (PET) studies challenged this theory, demonstrating a physiological "uncoupling" between brain blood flow and oxygen metabolism. These PET observations played a pivotal role in guiding the development of fMRI, by demonstrating which physiological parameters were most closely coupled to neuronal activity and by presaging the BOLD-contrast effect. Subsequent PET studies were crucial for constraining theories concerning the physiological mechanisms underlying hemodynamic/neuronal coupling and, thereby, guiding the development of models for quantification of oxygen metabolic rate $\% \Delta$ from fMRI. A firstperson account of the PET "coupling" studies and their influence on the development of fMRI is provided.
\end{abstract}

\section{Keywords}

PET; fMRI; coupling; cerebral blood flow; cerebral metabolic rate; $\mathrm{CBF}$; $\mathrm{CMRO}_{2}$

The need for a rigorous reassessment of the ninety-year old, nearly universally accepted hypothesis of Roy and Sherrington (Roy and Sherrington, 1890) -- that focal, stimulusinduced increases in brain blood flow are driven by local metabolic demand - was apparent to me by the Spring of 1982. Doing background reading in preparation for what was to be my first series of functional activation experiments, I was struck by the paucity of evidence establishing a chain of causality linking focal, physiological increases in neuronal activity with increases in regional cerebral blood flow (CBF.) Nevertheless, in the pre-PET functional brain mapping literature, the standard practice was to assert that increased neuronal activity was energetically expensive and caused increased metabolic demand that, in turn, up-regulated blood flow (e.g. (Roland and Larsen, 1976; Roland et al., 1980). While this was certainly a plausible scenario, it was far from rigorously demonstrated. When I

\footnotetext{
(C) 2012 Elsevier Inc. All rights reserved.
}

Publisher's Disclaimer: This is a PDF file of an unedited manuscript that has been accepted for publication. As a service to our customers we are providing this early version of the manuscript. The manuscript will undergo copyediting, typesetting, and review of the resulting proof before it is published in its final citable form. Please note that during the production process errors may be discovered which could affect the content, and all legal disclaimers that apply to the journal pertain. 
broached this striking lack of evidence for such a widely held belief with Marcus Raichle, my mentor, he agreed, and strongly encouraged me to pursue the issue experimentally.

The prospect of using ${ }^{15} \mathrm{O}$ tracers and PET for functional brain mapping had brought me to Washington University for a neurology residency in 1980. I majored in liberal arts and philosophy at St. Johns College in Annapolis, focusing my studies on the evolution of epistemology (i.e., the nature of scientific knowledge) from Aristotle to Descartes to Kant. When I applied to medical school, my vision was an academic career studying the neural bases of cognition. As a medical student at Georgetown University, I was fascinated by studies using ${ }^{133} \mathrm{Xe}$, single-photon imaging to map language, reasoning, memory and other high-order brain functions (e.g. (Larsen et al., 1978; Risberg and Ingvar, 1973; Roland and Larsen, 1976). Guided by my medical school mentor, neurologist Stanley Cohen, I was aware that Michel Ter-Pogossian, Chief of the Radiation Sciences Division at the Mallinckrodt Institute in Saint Louis, was well along in the process of implementing ${ }^{15} \mathrm{O}-$ based methods for PET measurements of brain hemodynamics and metabolism. TerPogossian had sited the first cyclotron in a medical institution, designed and built the first PET scanners, and selected ${ }^{15} \mathrm{O}$ as the molecular centerpiece of his laboratory. Marcus Raichle had been recruited into this team because of his experience in cerebral oxygen metabolism, gained both through studies of cerebral autoregulation as a resident at Cornel University and studies of high-altitude physiology, as a neurologist at Brooks Air Force base. In my residency interview, Raichle confirmed that Cohen's information was correct and that, if I wished, I could have access to this laboratory for human brain mapping studies. The Chair of Neurology, William Landau, endorsed this plan, indicating that I could use my elective rotations for research and could have additional post-graduate years funded under his NINDS T32 grant until I obtained my own funding. This convinced me. I arrived in Saint Louis in July, 1980 to start neurology residency.

\section{The CBF Stimulus-Rate Experiments}

Putting my long-term goal of mapping cognitive operations on temporary hold, I focused on the issue of neural-vascular coupling. An ideal experiment to explore the causal link between neuronal activity, metabolic rate and blood would simultaneously measure oxygen metabolism, glucose metabolism, and blood flow over a range of neural response intensities. In 1982, however, this wasn't a possibility. Glucose measurements using ${ }^{18} \mathrm{FDG}$ were being carried out at a handful of institutions, but this synthesis hadn't been implemented at Washington University. Oxygen metabolic rate $\left(\mathrm{CMRO}_{2}\right)$ measurements had been implemented several years earlier, using carotid injection of ${ }^{15} \mathrm{OO}$-labeled blood (Raichle et al., 1976), but were deemed too invasive to continue. $\mathrm{H}_{2}{ }^{15} \mathrm{O}$ CBF measurements were, however, in advanced stages of development and validation (Herscovitch et al., 1983; Herscovitch and Raichle, 1983). So, $\mathrm{H}_{2}{ }^{15} \mathrm{O}$ CBF measurements were the place to start.

The next decision points were to select a stimulus modality and develop an experimental design. In the course of an electro-encephalography rotation, I came across a pre-market advertising brochure from Grass instruments for a new visual-stimulation system (S10-VS), which consisted of a set of swimming goggles into which circuit boards holding an array of light-emitting diodes had been placed. The system delivered full-field flashes of fixed 
wavelength, luminance and duration over a range of frequencies from $1 \mathrm{~Hz}$ to $128 \mathrm{~Hz}$. Knowing that the time for full recovery of the visual-evoked potential (VEP) was in the range of $125 \mathrm{msec}$ and that $\mathrm{H}_{2}{ }^{15} \mathrm{O}$ PET measures integrated over a period of 40 seconds, I reasoned that the $\mathrm{CBF}$ response should be linear at least up to a repetition rate of $8 \mathrm{~Hz}$. While not providing insight into the physiological cascade producing the CBF response, at least this experiment would test whether there was a one-to-one relationship between a measure of neural response magnitude (i.e., the number of VEP's elicited during the scanning interval) and the hemodynamic response magnitude. I presented this experimental design to Marcus Raichle, who agreed that it was feasible and would be an important contribution.

Moving forward with this plan, the first obstacle we encountered was trying to obtain a set of the Grass goggles. The S10-VS, it turned out, was not yet available for purchase. The local company representative told me we would simply have to wait until they went into production. This posed a significant problem for me, as my research elective time was already scheduled. Lacking other options, I wrote directly to Mary Grass, the Grass CEO at the time. I explained my circumstances and requested a pre-release version of the goggles. They came by return mail, with no invoice. A gift from Mrs. Grass. This gift, as it turned out, would be put to extraordinarily good use.

I started a 6-month elective block in my $3^{\text {rd }}$ year of residency in January, 1983. Feeling an obligation to be thoroughly versed in all aspects of the PET procedures before recruiting volunteers, I performed my first experimental session on myself (Figure 1). As the rateresponse experiments were intended to test a hypothesis about hemodynamic physiology, we performed them in a fully quantitative manner. This implied having arterial access, to obtain a time-activity curve of blood tracer concentration. For my self-study, Marcus Raichle placed the arterial and venous catheters. The technicians put on the face mask, placed the Grass goggles over the eye-holes and adjusted the stimulus rates according to my instructions. Peter Herscovitch oversaw the data acquisition.

My self-experiment worked as well as I could have hoped. Robust, well-localized, rategraded CBF responses were present in visual cortex (Figure 2). Confident in the procedures, I performed the same experiment in nine healthy volunteers over the spring of 1983. To analyze, visualize and describe these findings, I developed techniques for global-value normalization, voxel-wise image subtraction and spatial normalization. The spatial normalization methods I developed for these experiments launched the Washington University tradition of reporting activation locations in stereotactic coordinates, a practice which was adopted nearly universally by the brain-mapping community. Once these methods were in place, the data could be analyzed.

The consistency of the responses was impressive. The rate-response function was present in every subject. CBF rose linearly with stimulus rate $(r=0.886 ; p<0.0005)$, reaching a peak value at $8 \mathrm{~Hz}$ (Figure 3a). Response locations also were tightly grouped, despite the crudeness of the spatial normalization methods. I submitted the manuscript in August, 1983 and it was accepted in October of the same year (Fox and Raichle, 1984); Figure 3a). The rate-response function soon was replicated and extended using a reversing checkerboard, 
constant-luminance stimulus (Fox and Raichle, 1985). Concurrently, we published a more formal description of the stereotactic method (Fox et al., 1985) and demonstrated that the responses could be detected equally well in the "raw counts" data, without conversion into physiological units, eliminating the need for arterial catheters in many studies (Fox et al., 1984). Based on this work, I received a five-year Teacher-Investigator Award from the National Institute of Neurological Disorders and Stroke (NS-0904), fulfilling my end of the bargain with William Landau.

In publishing the CBF rate-response data, Marcus Raichle and I emphasized that our results - despite indicating that hemodynamics were tightly coupled to neuronal activity -- did not resolve the core question(s) about physiological chain of causality (Fox and Raichle, 1984). We noted that

"whether a precise coupling exists between neuronal electrical activity and tissue metabolic rate remains a matter of controversy."

The most compelling indications that flow-metabolism uncoupling might exist, in our estimation, were observations in which increased neuronal activity (REM sleep, seizure, etc.) was associated with increased oxyhemoglobin concentration, or rising tissue $\mathrm{pO}_{2}$, falling $\mathrm{pCO}_{2}$, and rising $\mathrm{pH}$ (Leniger-Follert, 1984; Leniger-Follert and Hossmann, 1979; Santiago et al., 1984; Urbanics et al., 1978). Wilder Penfield, for example, reported regional hyperemia and hyperoxia during focal seizures observed intra-operatively (Penfield, 1971). Sidney Goldring, then Chief of Neurosurgery at Washington University, agreed with Penfield's observations and provided me with photographs of the effect (Figure 4). I considered this fairly compelling evidence that $\mathrm{CBF}: \mathrm{CMRO}_{2}$ uncoupling occurred, at least under some neuronal-activation conditions, and was anxious to more forward with more definitive experiments.

\section{The CBF: $\mathrm{CMRO}_{2}$ Experiments}

At the same time that our initial CBF rate-effect experiment was being performed and published, Mark Mintun, Marcus Raichle and colleagues were developing and validating (by comparison to a stochastic wash-out method in baboons) the "three-step method" for $\mathrm{CMRO}_{2}$ (Mintun et al., 1984). This now-classic approach uses sequential administration of three ${ }^{15} \mathrm{O}$ PET tracers $\left(\mathrm{H}_{2}{ }^{15} \mathrm{O}, \mathrm{C}^{15} \mathrm{O},{ }^{15} \mathrm{OO}\right)$ to make absolute measurements of $\mathrm{CBF}$ $\left(\mathrm{H}_{2}{ }^{15} \mathrm{O}\right), \mathrm{CBV}\left(\mathrm{C}^{15} \mathrm{O}\right)$, oxygen extraction fraction $\left(\mathrm{OEF} ;{ }^{15} \mathrm{OO}\right)$. From these three explicit measurements and measurement of blood $\mathrm{pO}_{2}$ (via arterial catheter), absolute $\mathrm{CMRO}_{2}$ can be computed. While time consuming and labor intensive, the method is undeniably rigorous and thoroughly validated, far more so than any subsequent $\mathrm{CMRO}_{2}$ method developed for PET or fMRI. Once these methods were in place and validated, we were ready to measure $\mathrm{CBF}$ and $\mathrm{CMRO}_{2}$ during functional activation.

Expecting that some degree of uncoupling was likely to be observed, we debated the best experimental design. Should we explore the rate effect using the Grass goggles? Or should we explore a stimulus-duration effect? We presumed from prior literature (above), that the uncoupling effect would have rapid onset; we weren't sure how long it might persist. We opted to pursue a duration effect, with stimulus durations of zero, one and five minutes prior 
to tracer delivery. Feeling that staring into the Grass goggles flashing at $8 \mathrm{~Hz}$ for 5 minutes would be unpleasant, I looked for alternatives. I spent a considerable amount of time reading the works of Vernon Mountcastle and others in the area of somatosensory stimulation, learning that vibrotactile stimulation can entrain cortical neurons at rates exceeding $200 \mathrm{~Hz}$. A few preliminary $\mathrm{H}_{2}{ }^{15} \mathrm{O}$ CBF studies confirmed that the response to finger-pad vibration was robust, non-fatiguing and readily tolerated. So, the choice was made to move forward with Mintun's three-step-method experiment using vibrotactile stimulation.

Even for resting-state measures, ${ }^{15} \mathrm{O} \mathrm{CBF}: \mathrm{CMRO}_{2}$ experiments are complex and time consuming, as three different radiotracers are administered while drawing arterial samples as rapidly as possible. To allow for radiotracer decay $\left(\mathrm{T}_{1 / 2}=123\right.$ seconds), tracers are administered at intervals of no shorter than ten minutes. Acquiring four different scan conditions (rest, $0 \mathrm{~min}, 1 \mathrm{~min}$, and $5 \mathrm{~min}$ ) for each of three different tracers takes a minimum of three hours. Placing the arterial and venous lines, immobilizing the head and performing the transmission scans adds another hour to the session. For each of nine subjects, I placed the arterial and venous lines, administered the radiotracers, oversaw data acquisition and reconstruction, and analyzed all the data. To ensure inter-subject procedural consistency, all the experiments were obtained over a period of a few months. There were fully analyzed by the Fall of 1984. The results were much as we had suspected.

$\mathrm{CBF}$, reliable as ever, rose robustly in every subject. CBV shadowed CBF: lower in magnitude, but just as consistent. $\mathrm{CMRO}_{2}$ rose weakly $(8 \%)$, not reaching statistical significance. The OEF response, on the other hand, was absolutely unequivocal. OEF fell by a highly significant $19 \%$, conclusively demonstrating that the blood flow increase far exceeded the oxygen demand. When performed using arterial sampling, PET provides absolute measures in physiological units (not just relative measurements as percent change). Because we obtained all data in a "fully quantitative" mode, we confirmed that CBF and $\mathrm{CMRO}_{2}$ were highly correlated at rest despite being uncorrelated during task. This motivated our description of the effect as "uncoupling". These results clearly contradicted the Roy and Sherrington postulate. They also contradicted a single-subject report that Marcus had published (Raichle et al., 1976), using the carotid-injection method.

Nevertheless, the data were scrupulously acquired and analyzed; they needed to be presented to the community. When I reviewed these data with Marcus, he encouraged me to submit them for the XII meeting of the International Society of Cerebral Blood Flow and Metabolism (ISCBF\&M), to be held in Ronneby-Lund, Sweden in June, 1985.

\section{Ronneby-Lund}

Auspicious signs: my abstract was assigned an oral presentation; I received a Scanditronix Travel Fellowship (one of two). The Scanditronix fellowship not only paid my way to Ronneby, it also funded a visit to Stockholm after the meeting. I was thrilled. This was my first trip outside the United States and my first presentation to an international audience. Before leaving Saint Louis, I gave my talk to the entire laboratory, getting practice fielding aggressive questions. The border control officer at Kastrup Airport gave my virgin passport its first stamp. In Ronneby, the night before my presentation, I rehearsed my talk repeatedly with Joel Perlmutter, a fellow former resident also working in Raichle's laboratory. Joel 
asked and re-asked every question he could think of until my replies were crisp and compelling. This was enormously helpful. I felt ready.

My talk was toward the end of the second morning session. The meeting room was large and packed, as there were no parallel sessions at ISCBF\&M. My talk proceeded smoothly as I presented the methods. When I moved onto the results, however, I was interrupted by shouts of disagreement (not questions or comments) from the audience. One person stood up and shouted that I overestimated my CBV correction. I paused, then continued. When the moderator opened the talk for questions, they came in a torrent. Some were complimentary but skeptical. Others were uncomplimentary and openly critical. I responded to each, providing well-rehearsed explanations, but did not win over my audience. The questions and comments continued at length, well beyond the time allotted for my talk and into that of the next two speakers. Not wishing to interrupt the dialogue, the moderator allowed this to continue until the end of the session. The two skipped talks from the morning session opened the afternoon session.

The end of the session didn't end the barrage of criticism. For the rest of the meeting, my conversations were monopolized by the aftermath of my presentation. Walking to lunch, eating lunch, over drinks, over dinner: everyone wanted to question, to criticize, to register incredulity. The harshest comments were that I was scientifically irresponsible and had no business presenting such controversial nonsense in this international venue. I know that Raichle received much the same treatment. Louis Sokoloff, inventor of the FDG method, wasn't shy about expressing his disapproval. In questioning metabolism as the mediator of flow, we seriously undermined the importance of the FDG method, long touted as the most direct imaging index of neuronal activity. Neither Raichle nor I, however, backed off of our findings. We knew that we had done our best and we knew what we had observed.

Returning from Sweden, Raichle wanted to be absolutely certain of our results before taking them to a peer-reviewed publication. The most telling criticism we had encountered was the possibility that the effects we were observing were transient (i.e., not steady state), despite the fact that we had demonstrated stability out to five minutes. Another was that the effect might be somatosensory-system specific. To address these, I carried stimulation out to 45 minutes in a small group of subjects. Same result. I also did some visual-stimulus and handmovement trials. Same result. With these data in hand, I was given the green light to submit the data to PNAS in October, four months after my presentation in Sweden.

The reviews returned quickly. The reviewers' responses were overwhelmingly positive and complimentary, despite the lambasting I had received in Ronneby. The work was considered "excellent", "revolutionary", with "unexpected results and bold conclusions" which "will open new avenues and greatly stimulate future research...". It was accepted with minor revisions and published in February (Fox and Raichle, 1986). At the time of writing, this manuscript has more than 1,000 citations.

\section{The CBF:CMRO ${ }_{2}: \mathrm{CMRgluc}$ Experiments}

In pondering the neuronal-hemodynamic-metabolic coupling puzzle, glucose metabolism was the piece hardest to fit into place. Based on the available literature, ${ }^{18} \mathrm{FDG}$ uptake rose 
substantially during task performance. Either this indicated that brain activation caused a metabolic pathway shift, from oxidative to glycolytic metabolism, or the ${ }^{18} \mathrm{FDG}$ literature was misleading. The possibility that the ${ }^{18} \mathrm{FDG}$ literature was spurious we took quite seriously. Because of the long half-life of ${ }^{18} \mathrm{~F}$ (110 minutes), no within-subject, task-rest comparisons had been published. This meant that our ${ }^{15} \mathrm{O}$ "gold-standard" of within-subject, within-session, task-control contrasts and voxel-wise subtractions hadn't been achieved. From our perspective, therefore, the ${ }^{18} \mathrm{FDG}$ literature was inconclusive and we pointedly commented on this in the discussion section of the somatosensory CBF:CMRO 2 paper (Fox and Raichle, 1986). The obvious next step was to "up the ante" and perform within-subject comparisons of $\mathrm{CBF}$ with $\mathrm{CMRO}_{2}$, and $\mathrm{CMRgluc}$.

The experimental design we adopted was paired measurement of $\mathrm{CBF}$ and $\mathrm{CMRO}_{2}$ in one group of subjects $(n=5)$ and paired measurement of CBF and CMRgluc in a second group of subjects $(n=5)$. Because of the long $T^{1 / 2}$ of ${ }^{18} \mathrm{~F}$, we waited an hour after completion of the first ${ }^{18} \mathrm{FDG}$ scan $(\sim 2$ hours after the first injection) before giving the second injection, and included a pre-scan to correct for residual tracer. For this series of experiments, we returned to the visual system. In collaboration with David Van Essen and John Allman, we had developed a constant-luminance, annular checkerboard stimulus for retinotopy studies (Fox et al., 1987; Fox et al., 1986). Delivered with a large, high-speed monitor, this system provided activation responses even more robust and more extensive than those obtained with the Grass S10-VS.

As anticipated, we saw highly significant CBF responses in each of the 10 subjects (Figure 5). The average response in each subject group was $49-50 \%$. As previously, $\mathrm{CMRO}_{2}$ showed only a weak increase (mean $=5 \%$ ). For the first time, we were able to demonstrate that the $\mathrm{CMRO}_{2}$ changes were statistically significant, but only by pooling data with our prior experiments. CMRgluc responses (51\% mean) closely matched the CBF responses. At rest, $\mathrm{CMRO}_{2}$ and $\mathrm{CMRgluc}$ were closely coupled, with a stoichiometric ratio of 4.1, closely matching previously reported values. During task, however, the CMRgluc increase were 10 fold greater than the $\mathrm{CMRO}_{2}$ increases. Clearly, the CMRgluc increases were not for the sake of the oxidative metabolism and probably not for ATP production, as had been assumed since the development of the FDG method. Rather, the hemodynamic and metabolic physiology associated with neuronal responses was far more complicated than anyone had expected.

These results were submitted to Science in March, 1988 and accepted in May (Fox et al., 1988). As with our PNAS submission, the reviewers' comments were highly complimentary, encouraging us to be bold in our conclusions. Regarding flow and metabolism coupling, we broadly concluded,

"traditional concepts of the dynamic regulation of cerebral metabolism and blood flow must be reconsidered."

And,

"blood flow increases during neural activity are regulated by a mechanism, and serve a need, other than oxidative metabolism." 
At a more specific level, we speculated that the disproportionate increase in CMRgluc (over $\mathrm{CMRO}_{2}$ ) might indicate a shift in metabolic pathway, from glucose oxidation to glycolysis.

If so, this would be associated with an increase in tissue lactate. As a possible cause for such a pathway shift, we drew attention to prior evidence that the brain might be near it's enzymatic capacity (of cytochrome oxidase) and unable to up-regulate respiration. Because of the clear surfeit of oxygen, we did not entertain the prospect of oxygen lack as being a viable mechanistic option.

In 1989, I accepted a position at the Mind-Brain Institute at Johns Hopkins University, ending my participation in the Washington University contributions to the "coupling controversy." My nine-years of training at Washington University had been enormously productive. I consider this a testimony to Ter-Pogossian's vision of the versatility of ${ }^{15} \mathrm{O}$ cornerstone for a PET research program and to the outstanding research environment provided by Ter-Pogossian, Raichle and the researchers they attracted to their laboratory. It was an honor to have worked with them.

\section{The Travelling Goggles}

Activation responses to the Grass goggles were remarkably reliable. So much so, that when Jack Belliveau called me to describe a new, contrast-enhanced magnetic resonance imaging (MRI) method for measuring cerebral blood volume (CBV) and asked for advice regarding stimulus selection, I told him that the Grass goggles were his best option. Being constructed of plastic and LED's, I was confident they would be MRI compatible. Jack agreed and I shipped the goggles to Boston. Thereafter, I got periodic calls from Jack with progress updates and questions. The most memorable questions were how to correct for spatialresolution-based magnitude differences between PET and fMRI and what were the expected proportionalities of CBF and CBV during activation. In 1991, Jack's project appeared on the cover of Science, in the now-classic paper introducing fMRI to an appreciative world (Belliveau et al., 1991). While I was disappointed not to be offered co-authorship, Jack won my undying gratitude by reporting his results in stereotactic coordinates. This established a precedent that fMRI researchers adopt the reporting standards used in the PET community, rather than creating their own. Well satisfied with the performance of the Grass goggles, Jack passed them on to Ken Kwong for use in the MGH's next stage of fMRI developments. Advised by Marcus Raichle, Segi Ogawa and the Minnesota group also purchased a set of Grass goggles for use in their inaugural fMRI experiments. One enormously enjoyable side effect of our controversial (and generally stressful) role in challenging the status quo was that it provided Marcus and myself ring-side seats for a dramatic, head-to-head competition between the world's leading MR groups to replicate -- or disprove -- our findings.

\section{The BOLD Experiments}

The first magnetic resonance test of our controversial "uncoupling" results came from Yale. Motivating his report by reference to our recent Science paper, James Prichard used Grass S10-VS goggles and ${ }^{1} \mathrm{H}$ magnetic resonance spectroscopy (MRS) to measure brain lactate during physiological stimulation (Prichard et al., 1991). As predicted, he found 
"lactate elevation occurs in the course of normal brain function, most probably due to a transient excess of glycolysis over respiration."

In 1992 the first descriptions of BOLD fMRI appeared in the literature. Three groups were in close competition: the MGH group, with Kenneth Kwong as lead author (Kwong et al., 1992); the University of Minnesota group, with Segi Ogawa as lead author (Ogawa et al., 1992); and the University of Wisconsin group, with Peter Bandettini as lead author (Bandettini et al., 1992). For all three groups, our $\mathrm{CBF}: \mathrm{CMRO}_{2} \mathrm{PET}$ results provided motivation for the developments, or an interpretive framework for the results, or both. Segi Ogawa (Ogawa et al., 1992) framed his group's interest in BOLD contrast by stating:

"positron emission tomography imaging experiments demonstrate stimulationproduced increases in regional cerebral blood flow without significantly changing local oxygen use, thus predicting an elevation in venous-blood oxygenation. This result suggested that BOLD contrast imaging could be used to map human mental operations."

Ogawa interpreted their results saying:

"the changes are caused by a stimulus-induced change in magnetic susceptibility that results from a reduced concentration of the paramagnetic species deoxyhemoglobin in venous blood. This interpretation is consistent with positron emission tomography experiments that show a large increase in regional blood flow and little increase in oxygen utilization, thus predicting a localized increase in venous blood oxygenation."

Choosing an experimental paradigm we had considered for our $\mathrm{CMRO}_{2}$ studies but not selected, Kwong extended our CBF rate-response observations to fMRI. In doing so, he precisely replicated the rate-response function we described previously (Fox and Raichle, 1984, 1985), using both a CBF-weighted inversion recovery (IR) pulse sequence and an oxygenation-weighted gradient echo (GE) pulse sequence (Figure 3b). From these, Kwong concluded:

"Our results independently confirm PET observations that activation-induced changes in blood flow and volume area accompanied by little or no increase in tissue oxygen consumption."

Needless to say, I was extremely gratified by these developments. I was pleased both that my prior work had motivated the development of such a novel imaging technique and pleased that the results so clearly confirmed our PET observations. Further, both Ogawa and Bandettini extended the "uncoupling" phenomenon to the motor system, putting another nail in the coffin of the argument that it was a system-specific effect. From this point forward, every time a BOLD paper reported brain activation in a new region, the generality of the uncoupling effect was confirmed and extended.

\section{Emerging Physiological Models}

Having demonstrated that fMRI could detect both task-driven changes in hemodynamics and hemodynamic-metabolic dissociation, physiological models to quantify $\mathrm{CMRO}_{2}$ and $\mathrm{OEF}$ 
using fMRI seemed tantalizingly close. Essential components of any such models, however, were the mathematical relationships posited between hemodynamics (CBF and CBV) and metabolism $\left(\mathrm{CMRO}_{2}\right)$ and, more fundamentally, the physiology upon which the mathematics were based. Conceptualizations of the physiology, however, were very much in flux. Our observation (with Prichard's confirmation) that $\mathrm{CMRO}_{2}$ and CMRgluc were dissociated argued in favor of the "enzymatic limitation" hypothesis, with metabolic pathway shifting from oxidative (rest) to glycolytic (task). An alternative hypothesis was that, despite the evident vascular hyperoxia during task, brain tissue might experience an oxygen debt, at least transiently, due to oxygen-diffusion limitation from the blood vessel to the active neurons. Addressing this issue, Malonek and Grinvald (Malonek and Grinvald, 1996) employed intrinsic-signal optical imaging to demonstrate brief, highly focal tissue hypoxia, followed by longer-lasting, more extensive hyperoxia. From this, they suggested that $\mathrm{O}_{2}$ demand might still be the factor driving $\mathrm{CBF}$ increases, with the brain's vasculature "watering the entire garden for the sake of one thirsty flower." Shortly thereafter, Science ran a review article re-addressing the "coupling controversy" at the ten-year anniversary of our 1988 Science paper (Barinaga, 1997). Interviewing many of the leading investigators in the field, she drew the conclusion that community consensus had now swung the other way.

The "thirsty flower" theory informed several models for computing $\mathrm{CMRO}_{2} \% \Delta$ from fMRI (Buxton and Frank, 1997; Hoge et al., 1999; Hyder et al., 1998). Unfortunately, all of these models produced $\mathrm{CMRO}_{2} \% \Delta$ values substantially greater (several fold higher) than those obtained by PET. In response, Mark Mintun (Mintun et al., 2001) performed CBF activation experiments under conditions of hypoxia. These confirmed that tissue hypoxia (i.e., increased $\mathrm{O}_{2}$ debt) did not enhance the $\mathrm{CBF}$ response. Mintun concluded that "thirsty flower" hypothesis was untenable and specifically criticized the underlying assumptions made by the fMRI models. Mintun extended this by demonstrating that the lactate/pyruvate ratio, on the other hand, did augment the CBF response, suggesting a key role of glycolysis in CBF regulation (Mintun et al., 2004). Despite completely undermining the central assumptions of the fMRI modeling methods, these papers were largely ignored by the fMRI community. From my seat on the sidelines, active participants in the coupling controversy appeared divided into the PET users and the fMRI users, each harboring deep suspicions about the other's methods and models. In the PET community, the fMRI models were regarded as unvalidated (in contrast to Mintun's rigorous validation of the ${ }^{15} \mathrm{O}$ PET method), incapable of measuring absolute values (i.e., only making \% change measurements), and heavily dependent upon assumed parameters, including the coupling ratio. In the MRI community, the PET models were looked upon as likely too complex and too slow (requiring three measurements spaced by 10 minutes) to be physiologically reliable, despite the paucity of assumed parameters.

\section{The Lin-Gao Papers: A Resolution}

In 1991, I accepted my current position, as Director of the Research Imaging Institute (RII) at the University of Texas Health Science Center in San Antonio. My move was motivated by a desire to have unimpeded access to both ${ }^{15} \mathrm{O}$ PET and MRI, something that I was unable to secure at Johns Hopkins. One of my first recruits to the new institute was Jia-Hong Gao, an expert in quantitative CBF measurements using MRI. Gao's recruitment reflected 
my belief that the future of studies in this area needed to be shaped by a group that was equally versed in both methods. As the coupling controversy evolved, Jia-Hong and I agreed that the only way to move forward was to bring the two imaging modalities into agreement. Physiologically, there was only one truth. If the modalities couldn't agree, the problem was with the methodologists. Still more pragmatically, if we hoped to combine the respective advantages of PET and fMRI to study hemodynamic and metabolic (e.g., mitochondrial) disorders, they needed to be in agreement.

Working under Jia-Hong and myself as co-mentors, a series of pre-doctoral students in our Medical Physics program attacked this problem, but without making significant headway. The impasse finally began to be breached when Ai-Ling Lin entered our program in 2002. Ai-Ling's strategy was relatively simple: apply accepted fMRI methods but make as few assumptions as possible and measure every possible parameter (Lin et al., 2008, 2009). Rather than assume a fixed relationship between CBF and CBV, measure both. Rather than take the parameters from literature as reliable, Ai-Ling re-visited the accuracy of the basal BOLD relaxation rate $(\mathrm{M})$ determination used in prior models. This approach worked. PET and MRI measurements of $\mathrm{CBF}$ and $\mathrm{CMRO}_{2}$ could be brought into agreement. In presenting these data to the MRI community, Ai-Ling was subjected to much the same brusque treatment I had received in Ronneby-Lund. (The imaging community does like to watch fights.) While this gave me some pangs of guilt, I was thrilled at the outcome. PET and fMRI were finally in agreement, and our original "uncoupling" papers again proven correct (Lin et al., 2010).

To interpret her findings, however, Ai-Ling turned away from both of the previously dominant theories (enzymatic capacity and oxygen debt) regarding CBF control. Instead, she looked to a much more complex model: the astrocyte-neuron lactate shuttle (ANLS) model of Pellerin and Magistretti (Pellerin and Magistretti, 1994). By the ANLS model, oxygen consumption is predominantly neuronal, while glia preferentially consume glucose. Further, the bulk of the glucose consumed during neuronal activation is for the sake of glutamate, an excitatory neurotransmitter. By the ANLS model, task-induced increases in neuronal activity have minimal energy demands. CBF up-regulation is chiefly driven by the lactate generated by in the course of glutamate shuttling. As judged by citations and review articles (e.g., (Attwell et al., 2010), community consensus now favors complex, multi-factorial explanations of the underlying physiology. How long this theory will prevail remains to be seen. In any event, the prediction of the reviewer of our original "uncoupling paper", that our paper "will open new avenues and greatly stimulate future research...", proved prescient. The ${ }^{15} \mathrm{O}$ PET "uncoupling" studies provided a substantial impetus to the field of neuroimaging, driving the development of new imaging methods and promoting a much deeper understanding of the underlying physiology.

\section{Acknowledgments}

I thank the outstanding team of scientists in the Division of Radiation Sciences at Washington University who encouraged and contributed to the worked described here, most notably Marcus Raichle, Michel Ter-Pogossian, Mark Mintun, and Peter Hercovitch. I thank Ai-Ling Lin for her tireless and ultimately successful efforts to solve a problem that I could not solve and I thank Jia-Hong Gao for guiding Ai-Ling in this endeavor. I thank the several persons who provided constructive criticism regarding this manuscript, including Peter Bandettini, Karl Friston, AiLing Lin and my wife, Sarabeth,. PTF is currently funded by the Research Imaging Institute and the Department of 
Radiology of the University of Texas Health Science Center at San Antonio, by the South Texas Veterans Health Care System, by the National Institutes of Health (MH74457, RR024387, MH084812, NS062254, AA019691) and by the Congressionally Directed Medical Research Program (W81XWH0820112).

\section{References}

Attwell D, Buchan AM, Charpak S, Lauritzen M, Macvicar BA, Newman EA. Glial and neuronal control of brain blood flow. Nature. 2010; 468:232-243. [PubMed: 21068832]

Bandettini PA, Wong EC, Hinks RS, Tikofsky RS, Hyde JS. Time course EPI of human brain function during task activation. Magn Reson Med. 1992; 25:390-397. [PubMed: 1614324]

Barinaga M. What makes brain neurons run? Science. 1997; 276:196-198. [PubMed: 9132940]

Belliveau JW, Kennedy DN Jr, McKinstry RC, Buchbinder BR, Weisskoff RM, Cohen MS, Vevea JM, Brady TJ, Rosen BR. Functional mapping of the human visual cortex by magnetic resonance imaging. Science. 1991; 254:716-719. [PubMed: 1948051]

Buxton RB, Frank LR. A model for the coupling between cerebral blood flow and oxygen metabolism during neural stimulation. J Cereb Blood Flow Metab. 1997; 17:64-72. [PubMed: 8978388]

Fox PT, Miezin FM, Allman JM, Van Essen DC, Raichle ME. Retinotopic organization of human visual cortex mapped with positron-emission tomography. J Neurosci. 1987; 7:913-922. [PubMed: 3494107]

Fox PT, Mintun MA, Raichle ME, Herscovitch P. A noninvasive approach to quantitative functional brain mapping with $\mathrm{H} 2$ (15)O and positron emission tomography. J Cereb Blood Flow Metab. 1984; 4:329-333. [PubMed: 6470051]

Fox PT, Mintun MA, Raichle ME, Miezin FM, Allman JM, Van Essen DC. Mapping human visual cortex with positron emission tomography. Nature. 1986; 323:806-809. [PubMed: 3534580]

Fox PT, Perlmutter JS, Raichle ME. A stereotactic method of anatomical localization for positron emission tomography. J Comput Assist Tomogr. 1985; 9:141-153. [PubMed: 3881487]

Fox PT, Raichle ME. Stimulus rate dependence of regional cerebral blood flow in human striate cortex, demonstrated by positron emission tomography. J Neurophysiol. 1984; 51:1109-1120. [PubMed: 6610024]

Fox PT, Raichle ME. Stimulus rate determines regional brain blood flow in striate cortex. Ann Neurol. 1985; 17:303-305. [PubMed: 3873210]

Fox PT, Raichle ME. Focal physiological uncoupling of cerebral blood flow and oxidative metabolism during somatosensory stimulation in human subjects. Proc Natl Acad Sci U S A. 1986; 83:11401144. [PubMed: 3485282]

Fox PT, Raichle ME, Mintun MA, Dence C. Nonoxidative glucose consumption during focal physiologic neural activity. Science. 1988; 241:462-464. [PubMed: 3260686]

Herscovitch P, Markham J, Raichle ME. Brain blood flow measured with intravenous H2(15)O. I. Theory and error analysis. J Nucl Med. 1983; 24:782-789. [PubMed: 6604139]

Herscovitch P, Raichle ME. Effect of tissue heterogeneity on the measurement of cerebral blood flow with the equilibrium C15O2 inhalation technique. J Cereb Blood Flow Metab. 1983; 3:407-415. [PubMed: 6415076]

Hoge RD, Atkinson J, Gill B, Crelier GR, Marrett S, Pike GB. Investigation of BOLD signal dependence on cerebral blood flow and oxygen consumption: the deoxyhemoglobin dilution model. Magn Reson Med. 1999; 42:849-863. [PubMed: 10542343]

Hyder F, Shulman RG, Rothman DL. A model for the regulation of cerebral oxygen delivery. J Appl Physiol. 1998; 85:554-564. [PubMed: 9688733]

Kwong KK, Belliveau JW, Chesler DA, Goldberg IE, Weisskoff RM, Poncelet BP, Kennedy DN, Hoppel BE, Cohen MS, Turner R, et al. Dynamic magnetic resonance imaging of human brain activity during primary sensory stimulation. Proc Natl Acad Sci U S A. 1992; 89:5675-5679. [PubMed: 1608978]

Larsen B, Skinhoj E, Lassen NA. Variations in regional cortical blood flow in the right and left hemispheres during automatic speech. Brain. 1978; 101:193-209. [PubMed: 667597]

Leniger-Follert E. Mechanisms of regulation of cerebral microflow during bicuculline-induced seizures in anaesthetized cats. J Cereb Blood Flow Metab. 1984; 4:150-165. [PubMed: 6725427] 
Leniger-Follert E, Hossmann KA. Simultaneous measurements of microflow and evoked potentials in the somatomotor cortex of the cat brain during specific sensory activation. Pflugers Arch. 1979; 380:85-89. [PubMed: 572043]

Lin AL, Fox PT, Hardies J, Duong TQ, Gao JH. Nonlinear coupling between cerebral blood flow, oxygen consumption, and ATP production in human visual cortex. Proc Natl Acad Sci U S A. 2010; 107:8446-8451. [PubMed: 20404151]

Lin AL, Fox PT, Yang Y, Lu H, Tan LH, Gao JH. Evaluation of MRI models in the measurement of CMRO2 and its relationship with CBF. Magn Reson Med. 2008; 60:380-389. [PubMed: 18666102]

Lin AL, Fox PT, Yang Y, Lu H, Tan LH, Gao JH. Time-dependent correlation of cerebral blood flow with oxygen metabolism in activated human visual cortex as measured by fMRI. NeuroImage. 2009; 44:16-22. [PubMed: 18804541]

Malonek D, Grinvald A. Interactions between electrical activity and cortical microcirculation revealed by imaging spectroscopy: implications for functional brain mapping. Science. 1996; 272:551-554. [PubMed: 8614805]

Mintun MA, Lundstrom BN, Snyder AZ, Vlassenko AG, Shulman GL, Raichle ME. Blood flow and oxygen delivery to human brain during functional activity: theoretical modeling and experimental data. Proc Natl Acad Sci U S A. 2001; 98:6859-6864. [PubMed: 11381119]

Mintun MA, Raichle ME, Martin WR, Herscovitch P. Brain oxygen utilization measured with O-15 radiotracers and positron emission tomography. J Nucl Med. 1984; 25:177-187. [PubMed: 6610032]

Mintun MA, Vlassenko AG, Rundle MM, Raichle ME. Increased lactate/pyruvate ratio augments blood flow in physiologically activated human brain. Proc Natl Acad Sci U S A. 2004; 101:659_ 664. [PubMed: 14704276]

Ogawa S, Tank DW, Menon R, Ellermann JM, Kim SG, Merkle H, Ugurbil K. Intrinsic signal changes accompanying sensory stimulation: functional brain mapping with magnetic resonance imaging. Proc Natl Acad Sci U S A. 1992; 89:5951-5955. [PubMed: 1631079]

Pellerin L, Magistretti PJ. Glutamate uptake into astrocytes stimulates aerobic glycolysis: a mechanism coupling neuronal activity to glucose utilization. Proc Natl Acad Sci U S A. 1994; 91:1062510629. [PubMed: 7938003]

Penfield W. Remarks on incomplete hypotheses for the control of cerebral circulation. J Neurosurg. 1971; 35:124-127. [PubMed: 4998938]

Prichard J, Rothman D, Novotny E, Petroff O, Kuwabara T, Avison M, Howseman A, Hanstock C, Shulman R. Lactate rise detected by 1H NMR in human visual cortex during physiologic stimulation. Proc Natl Acad Sci U S A. 1991; 88:5829-5831. [PubMed: 2062861]

Raichle ME, Grubb RL Jr, Gado MH, Eichling JO, Ter-Pogossian MM. Correlation between regional cerebral blood flow and oxidative metabolism. In vivo studies in man. Arch Neurol. 1976; 33:523526. [PubMed: 942309]

Risberg J, Ingvar DH. Patterns of activation in the grey matter of the dominant hemisphere during memorizing and reasoning. A study of regional cerebral blood flow changes during psychological testing in a group of neurologically normal patients. Brain. 1973; 96:737-756. [PubMed: 4773864]

Roland E, Larsen B. Focal increase of cerebral blood flow during stereognostic testing in man. Arch Neurol. 1976; 33:551-558. [PubMed: 942312]

Roland PE, Skinhoj E, Lassen NA, Larsen B. Different cortical areas in man in organization of voluntary movements in extrapersonal space. J Neurophysiol. 1980; 43:137-150. [PubMed: 7351548]

Roy CS, Sherrington CS. On the Regulation of the Blood-supply of the Brain. J Physiol. 1890; 11:85158.17.

Santiago TV, Guerra E, Neubauer JA, Edelman NH. Correlation between ventilation and brain blood flow during sleep. J Clin Invest. 1984; 73:497-506. [PubMed: 6421878]

Urbanics R, Leniger-Follert E, Lubbers DW. Time course of changes of extracellular H+ and K+ activities during and after direct electrical stimulation of the brain cortex. Pflugers Arch. 1978; 378:47-53. [PubMed: 32522] 


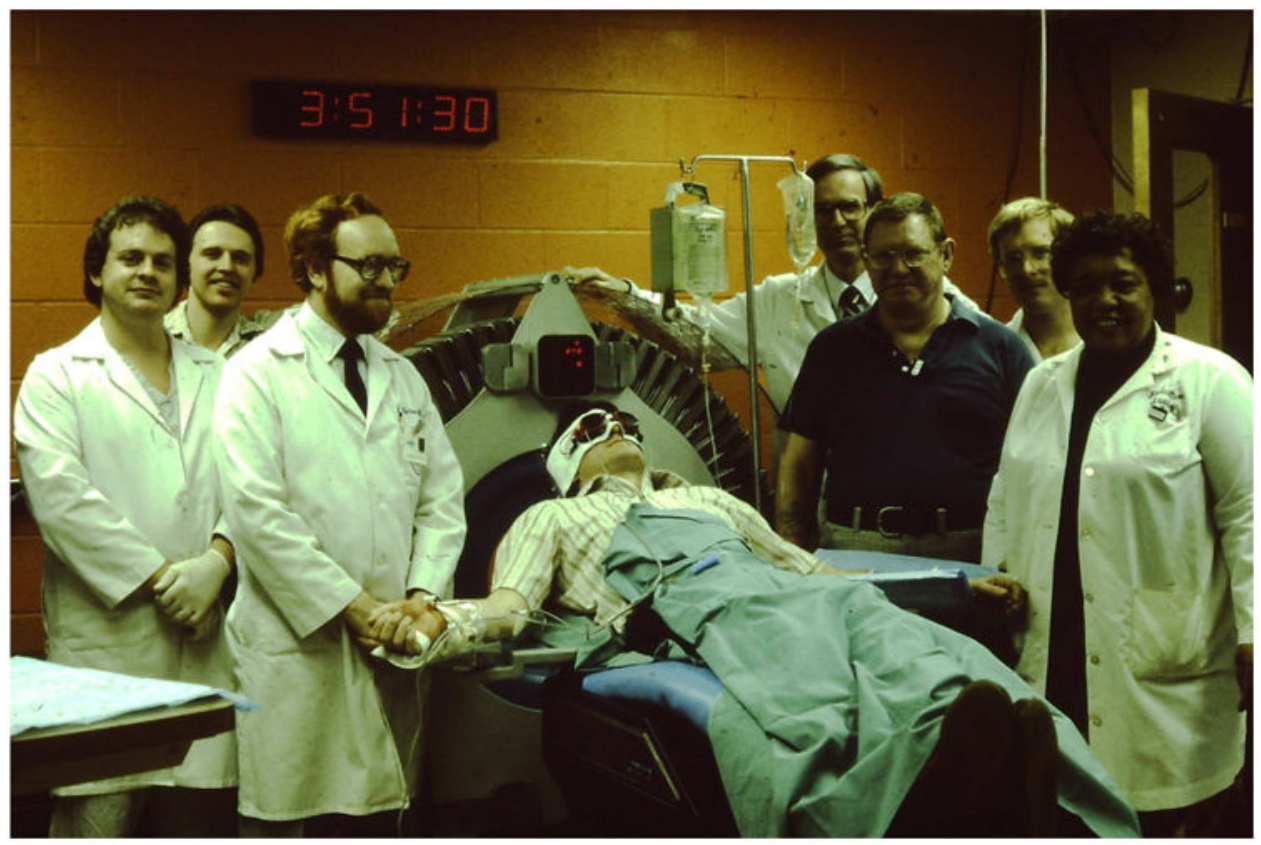

Figure 1.

The team performing the visual-stimulation, rate-response pilot study is shown. The author (PTF) is in the scanning chair, wearing the Grass S10-VS goggles mounted over the eyeholes of a thermoplastic mask, used for head restraint. A radial arterial catheter is placed in the right wrist and an intravenous catheter is placed in the left anti-cubital fossa. Peter Herscovitch is third from the left. Marcus Raichle is fourth from the right. The scanner is a PETT VI, manufactured by PETT Electronics, a spin-off company created by M. TerPogossian. 


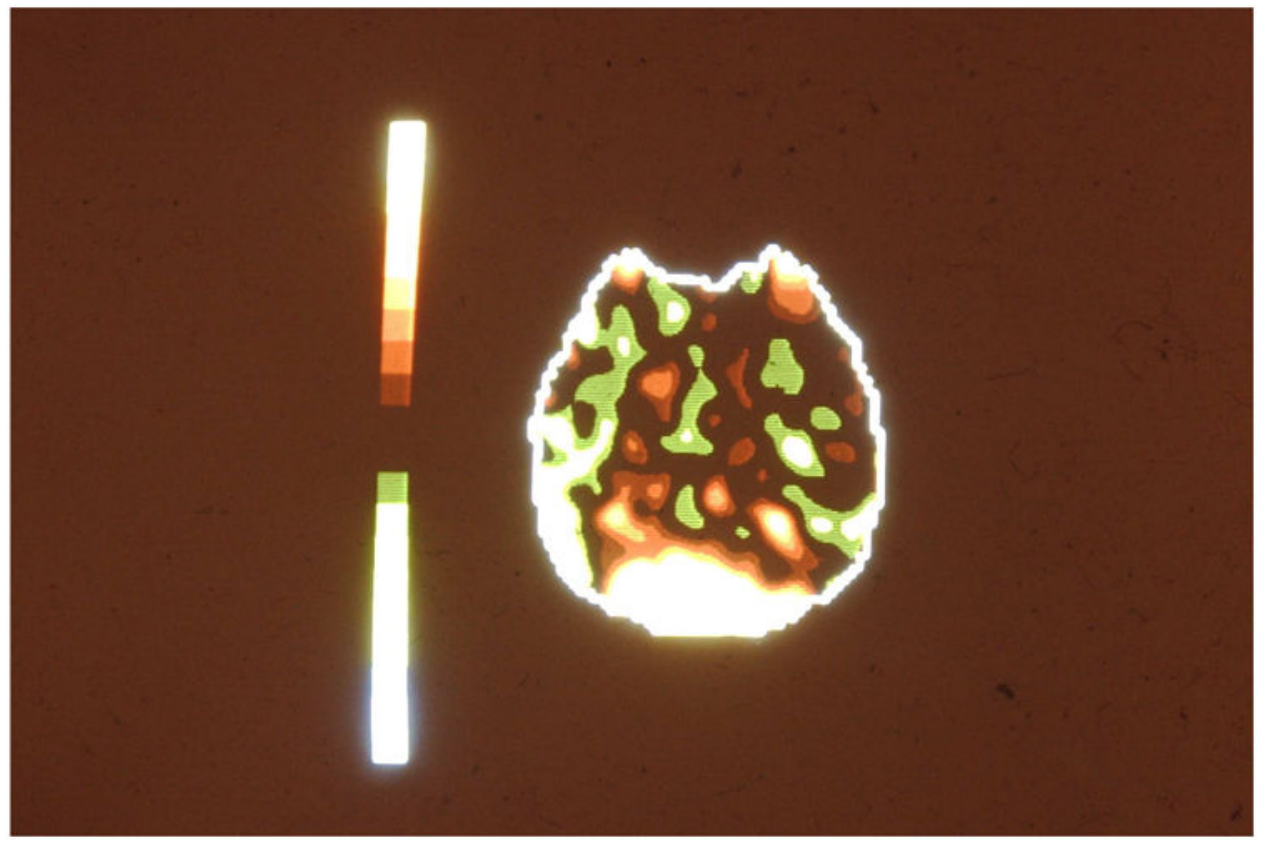

Figure 2.

The image is $\mathrm{CBF} \% \Delta$ ( $8 \mathrm{~Hz}$ stimulation minus rest) in an axial plane passing through the visual cortex of the author (PTF), obtained during the scanning session shown in Figure 1. The response produced by the Grass goggles was readily apparent even in a single image frame (40 seconds) in a single subject. 


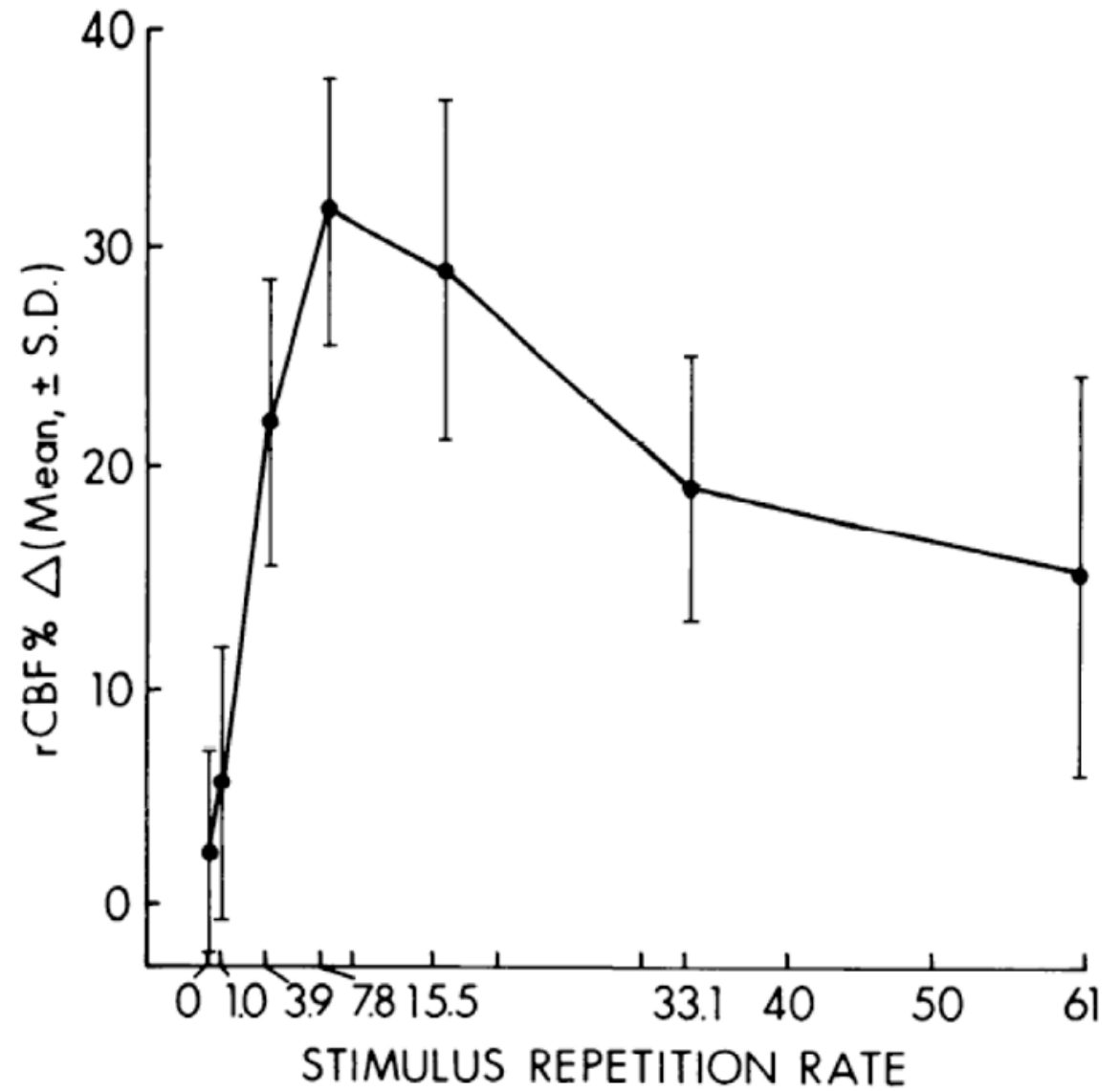

$3 a$

Neuroimage. Author manuscript; available in PMC 2014 May 13. 


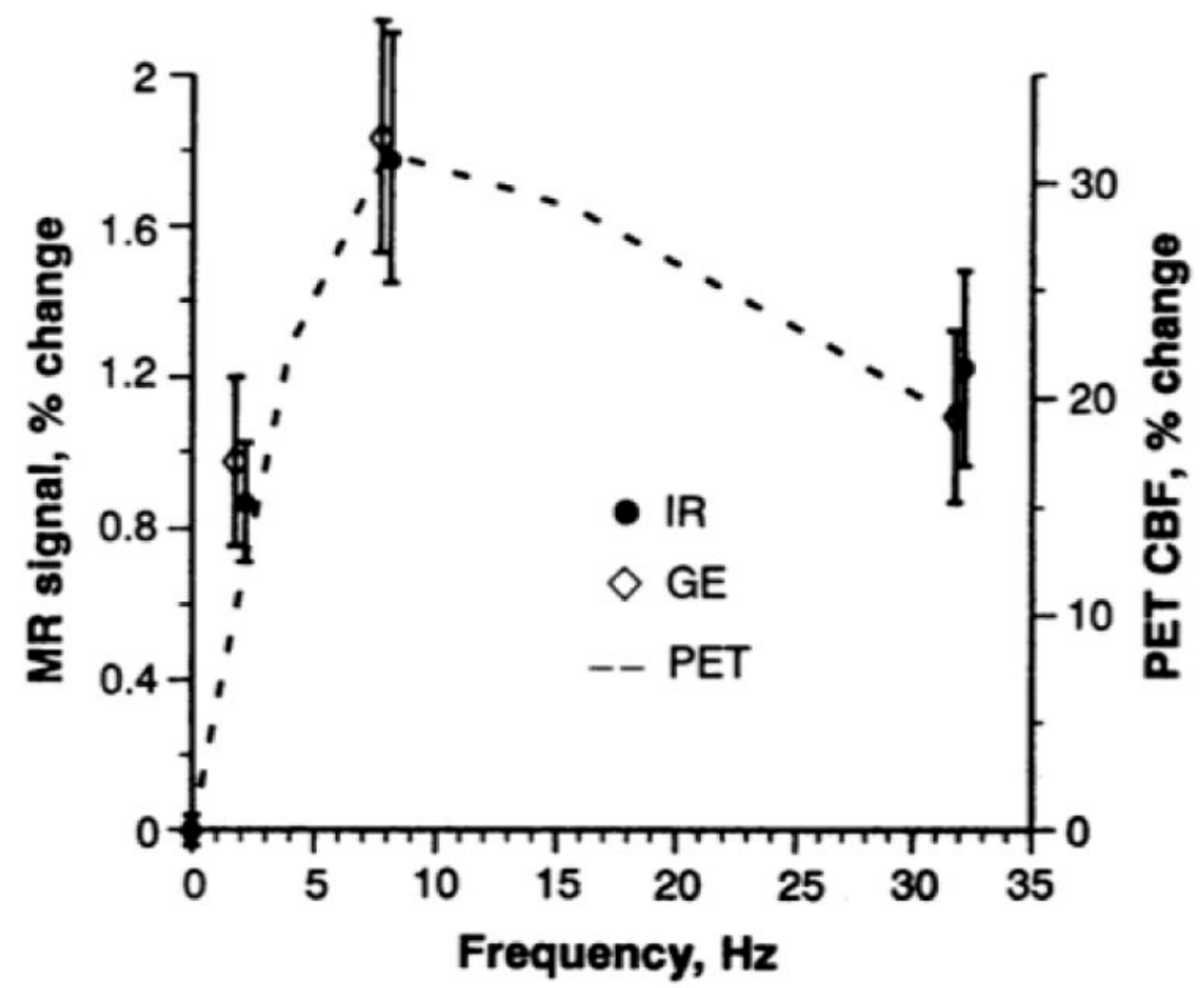

$3 b$

Figure 3.

Rate-response functions obtained from the Grass S10-VS visual-stimulation goggles are shown. Panel A shows the rate-response function obtained with $\mathrm{H}_{2}{ }^{15} \mathrm{O}$ PET (Fox and Raichle, 1984). Panel B shows the rate-response functions obtained by inversion recovery (IR; flow weighted) and gradient echo (GE; oxygenation weighted) BOLD fMRI overlaid on the PET response function (Kwong et al., 1992). 


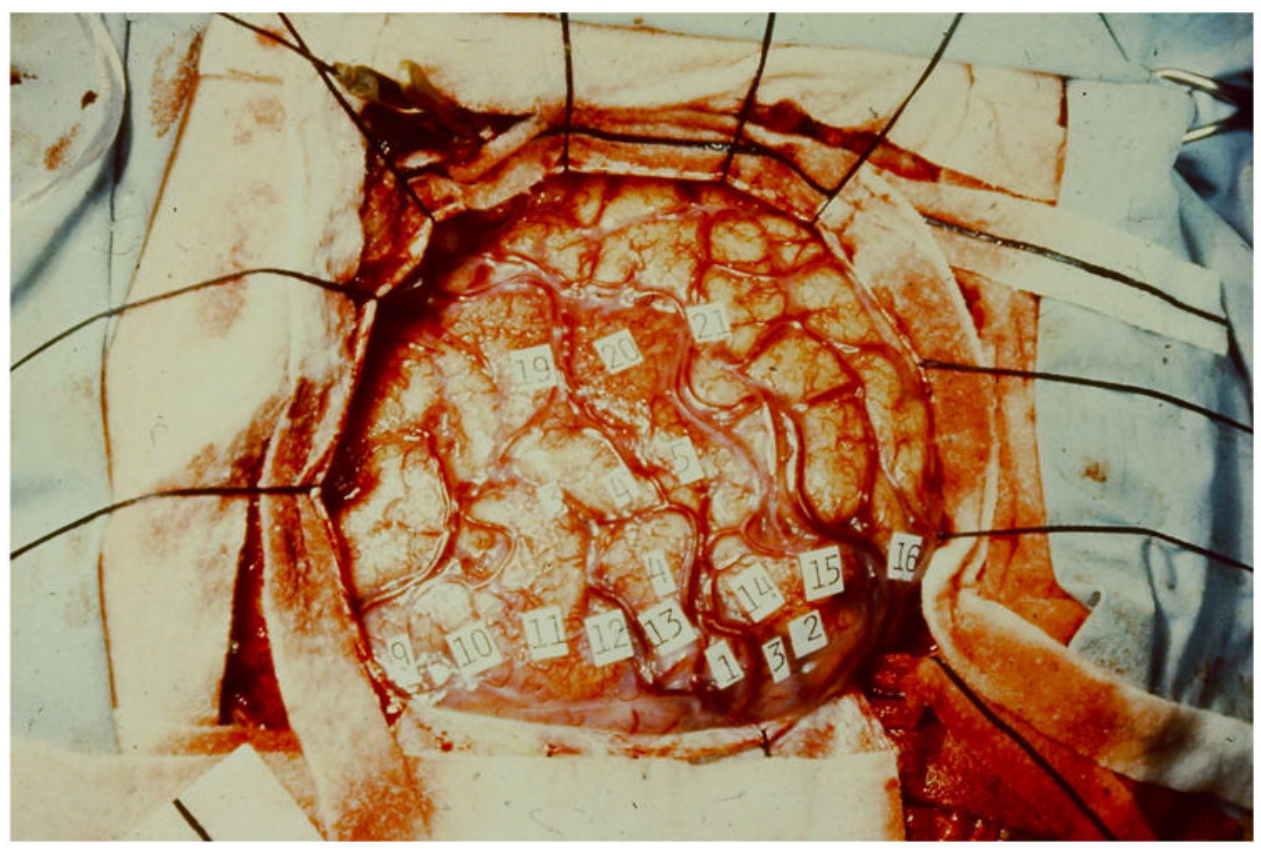

Figure 4.

The image is intra-operative photograph (courtesy of Sidney Goldring) of an epileptogenic lesion (an arteriovenous malformation) abutting the primary motor cortex mouth region. Circumscribed hyperemia and hyperoxia is seen under "ticket" 20 , during a focal motor seizure of the mouth region. The phenomenon of seizure-induced hyperemia/hyperoxia was described by Wilder Penfield (Penfield, 1971). Other authors (Leniger-Follert, 1984) reported similar findings in other preparations. 


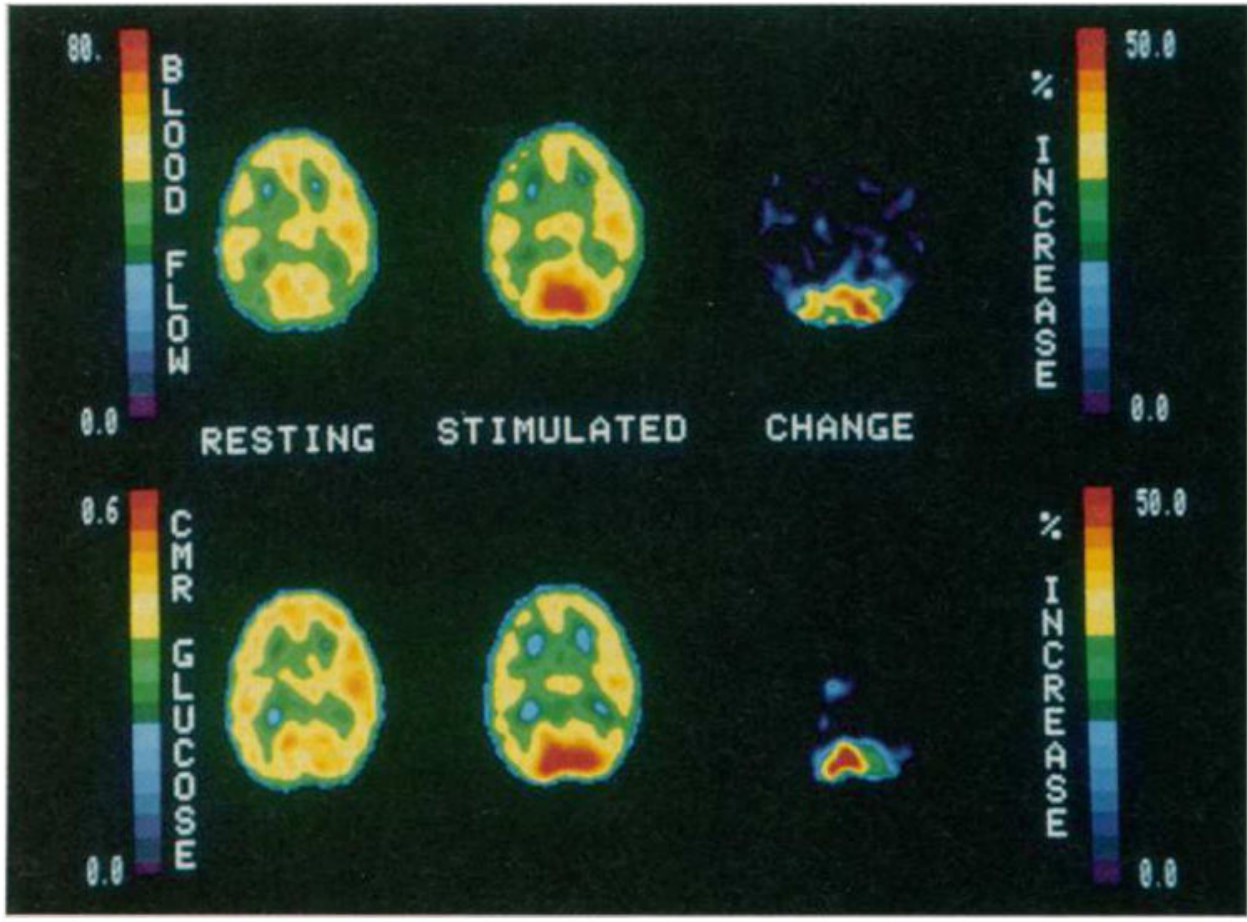

$5 a$

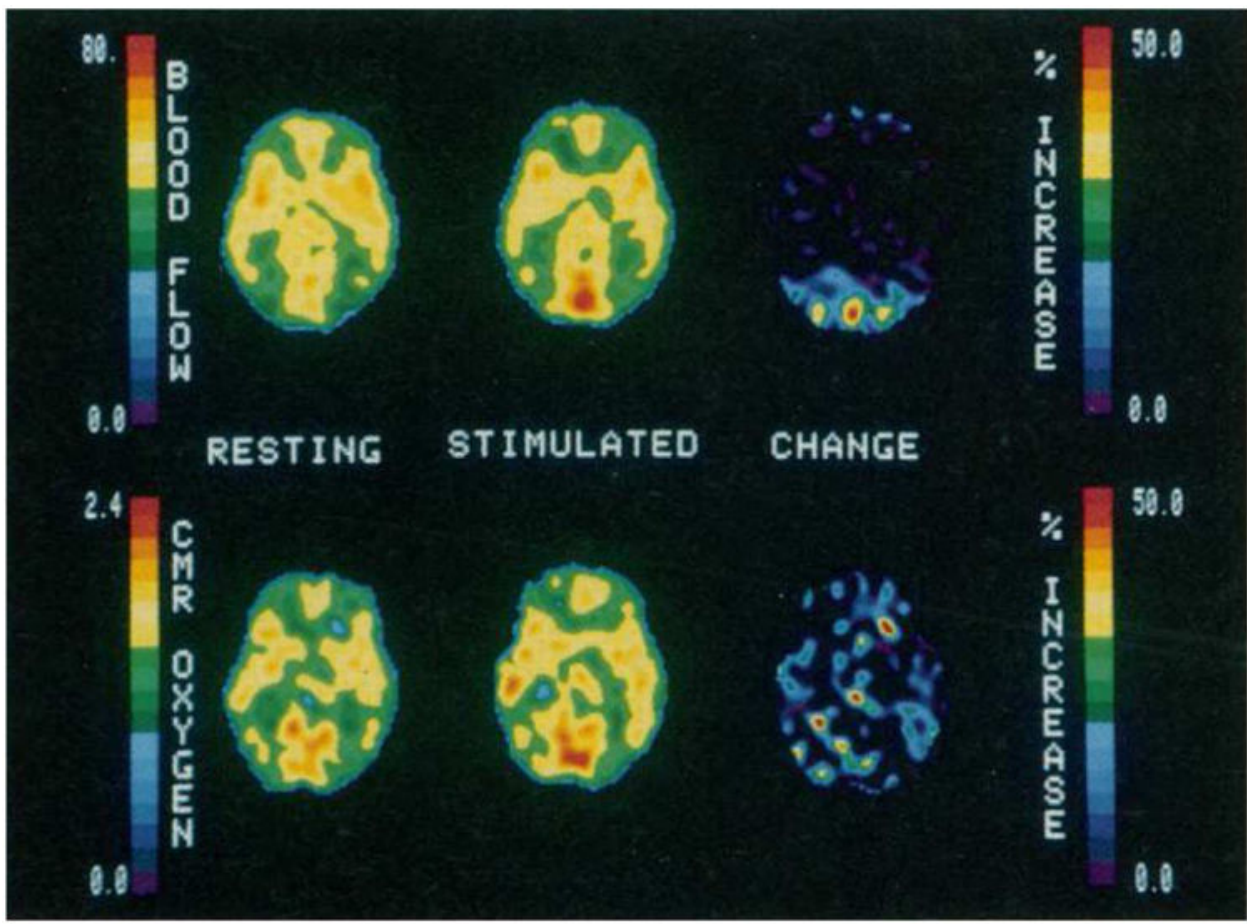

$5 b$

Figure 5. 
$\mathrm{CBF}: \mathrm{CMRO}_{2}$ :CMRgluc uncoupling. Within-subject comparisons of the relative magnitudes of the $\mathrm{CBF}$ and $\mathrm{CMRgluc}$ responses (panel $\mathrm{A}$ ) and of the $\mathrm{CBF}$ and $\mathrm{CMRO} 2$ responses (Panel B) to $10 \mathrm{~Hz}$ visual stimulation. (Reproduced from Fox et al., 1988.) 